\title{
Cervical interspinous bursitis in active polymyalgia rheumatica
}

\author{
C Salvarani, ${ }^{1}$ L Barozzi, ${ }^{2}$ F Cantini, ${ }^{3}$ L Niccoli, ${ }^{3}$ L Boiardi, ${ }^{1}$ M Valentino, ${ }^{2}$ N Pipitone, \\ G Bajocchi, ${ }^{1}$ P Macchioni, ${ }^{1}$ M G Catanoso, ${ }^{1}$ I Olivieri, ${ }^{4}$ G G Hunder ${ }^{5}$
}

\begin{abstract}
See Editorial, p 733
${ }^{1}$ Divisione di Reumatologia, Arcispedale S Maria Nuova, Reggio Emilia, Italy; ${ }^{2}$ Radiologia Diagnostica, Ospedale S OrsolaMalpighi, Bologna, Italy; ${ }^{3}$ II Divisione di Medicina, Unità Reumatologica, Ospedale di Prato, Prato, Italy; ${ }^{4}$ Dipartimento di Reumatologia, Ospedale S Carlo, Potenza e Ospedale Madonna delle Grazie, Matera, Italy; ${ }^{5}$ Mayo Clinic, Rochester, Minnesota, USA

Correspondence to:

Dr C Salvarani, Unità Operativa di Reumatologia, Arcispedale $S$ Maria Nuova, $V$ le Risorgimento N80, 42100 Reggio Emilia, Italy; salvarani.carlo@asmn.re.it
\end{abstract}

Accepted 6 January 2008 Published Online First

21 January 2008

\section{ABSTRACT \\ Objective: To evaluate the inflammatory involvement of cervical interspinous bursae in patients with polymyalgia rheumatica (PMR) using MRI.}

Methods: In all, 12 consecutive, untreated new patients with PMR were investigated. Five patients with fibromyalgia, two patients with cervical osteoarthritis and six patients with spondyloarthritis with neck pain served as controls. MRI of the cervical spine was performed in all 12 PMR case patients and in 13 control patients. Two of the four patients with PMR with pelvic girdle pain also had MRI of the lumbar spine.

Results: MRI evidence of interspinous cervical bursitis was found in all patients with PMR, and in three patients with fibromyalgia, in two with psoriatic spondylitis and one with cervical osteoarthritis. A moderate to marked (grade $\geqslant 2$ on a semiquantitative $0-3$ scale) cervical bursitis occurred significantly more frequently in patients with PMR than in control patients $183.3 \%$ compared with $30.7 \%, p=0.015)$. In all patients and controls with cervical bursitis the involvement was found at the C5-C7 cervical interspaces. MRI of the lumbar spine showed lumbar interspinous bursitis at the L3-L5 lumbar interspaces in the two patients with PMR and pelvic girdle pain examined.

Conclusions: Cervical interspinous bursitis is a likely basis for discomfort in the neck of patients with PMR. The prominent inflammatory involvement of cervical bursae supports the hypothesis that PMR is a disorder of prominent involvement of extra-articular synovial structures.

Polymyalgia rheumatica (PMR) is an inflammatory condition of unknown aetiology characterised by aching and stiffness in the cervical region, and shoulder and pelvic girdles. Shoulder pain is the presenting finding in the majority of patients (70$95 \%)$, whereas the neck and hips are less frequently involved (50-70\%). ${ }^{1}$ A mild synovitis with infiltrations of macrophages and CD4+ T-lymphocytes has been described in specimens of shoulder synovial membrane of patients with PMR. ${ }^{2}$ The presence of synovitis in patients with PMR has been documented by scintigraphy, magnetic resonance imaging (MRI) and ultrasonography (US). ${ }^{3-6}$ MRI and US have delineated involvement of proximal periarticular synovial structures. ${ }^{4-6}$ Bilateral subacromial bursitis and trochanteric bursitis are the most frequent lesions and are present in most patients with PMR who have pain in the shoulder and pelvic girdles, respectively. Therefore, we have suggested that PMR could be classified as an inflammatory process that primarily involves the extra-articular synovial structures (in particular bursae) in middle aged and older people. $^{78}$

In two pivotal studies, Bywaters in 1982 described the anatomy of cervical interspinous and lumbar interspinous bursae and their involvement in arthritis (fig 1). ${ }^{9}{ }^{10}$ Blockman et al studying fluorodeoxyglucose (FDG) uptake in patients with isolated PMR, without signs of giant cell arteritis (GCA) on temporal artery biopsy, observed abnormal FDG uptake in the shoulders and hips of most of the patients in keeping with the synovial inflammatory nature of the disease. ${ }^{11}$ Half of the patients also had increased FDG uptake in the region of the spinous processes of the cervical and lumbar vertebrae. However, FDG positron emission tomography (FDG-PET) scans were not able to identify the anatomical structures involved in the spinal inflammatory process in PMR due to low resolution.

Therefore we decided to use MRI to study the involvement of the cervical interspinous bursae in a series of consecutive patients who had symptoms of active PMR.

\section{PATIENTS AND METHODS}

Consecutive patients who were seen at the Prato and Reggio Emilia rheumatology centres, Italy, during a 6-month period and who satisfied criteria for $\mathrm{PMR}^{1}$ were considered suitable candidates for the study. Table 1 shows the clinical, demographic and MRI findings in the 12 case patients. None of the case patients had clinical or histological evidence of GCA or had been previously treated with corticosteroids.

The control group consisted of seven patients with non-inflammatory or mildly inflammatory conditions (five with fibromyalgia and two with cervical osteoarthritis) and six patients with spondyloarthritis (four with primary ankylosing spondylitis (AS) fulfilling the modified New York criteria $^{12}$ and two with psoriatic spondylitis) seen consecutively in the same centres after the patients with PMR. All the control patients had neck pain. The patients with spondyloarthritis had active disease and were treated with non-steroidal antiinflammatory drugs only.

MRI of the cervical spine was performed in all the 12 PMR and 13 control patients. Two of the four patients with PMR with pelvic girdle pain also had MRI of the lumbar spine.

MRI was performed using a $1 \mathrm{~T}$ superconductive magnet system (Signa Horizon LX; GE Medical Systems, Milwaukee, Wisconsin, USA). Patients were placed supine, in the standard position. Pulse sequences at cervical and lumbar level included 

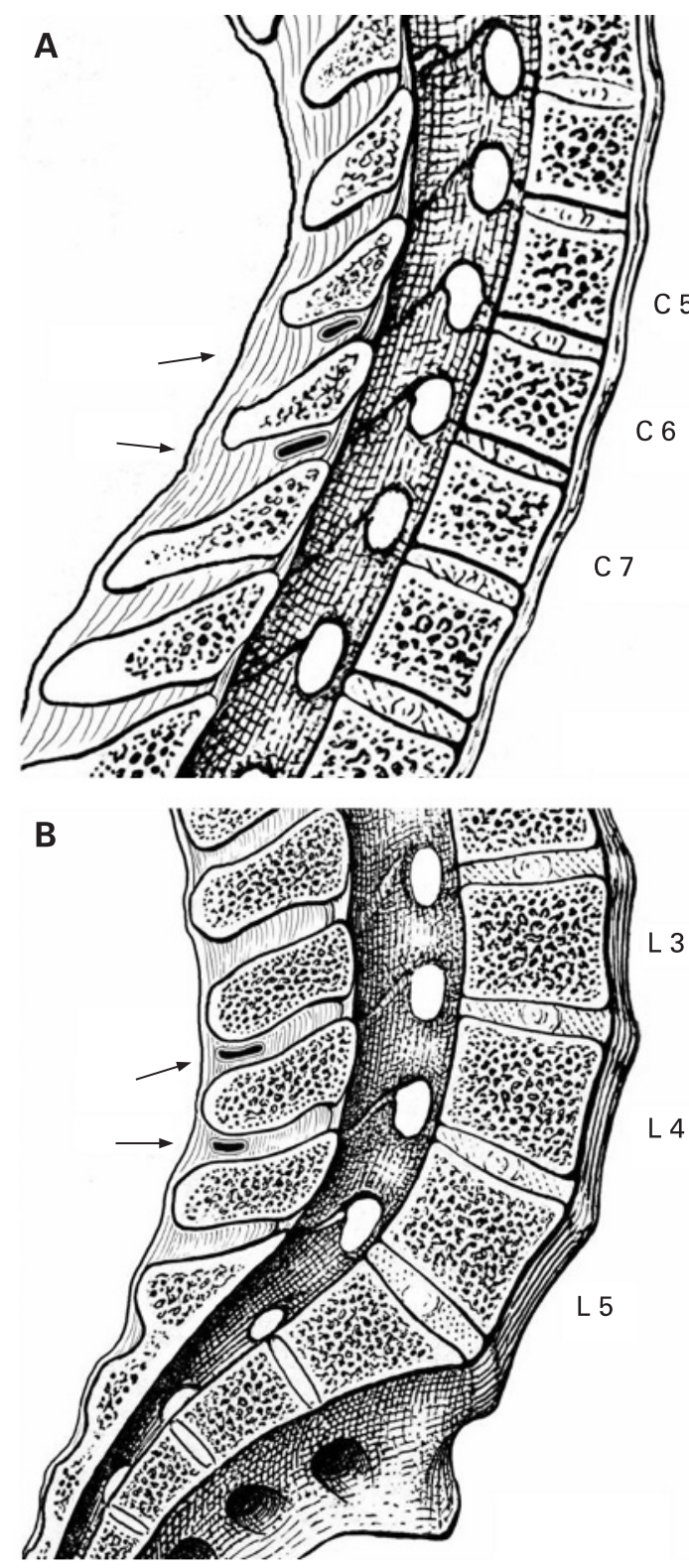

Figure 1 Location of the interspinous bursae. A. Median sagittal section through C5-C7 of the vertebral column. Cervical interspinous bursae lie anteriorly in $\mathrm{C} 6-\mathrm{C} 7$ interspinous spaces (arrows). B. Median sagittal section through L3-L5 of the vertebral column. Lumbar interspinous bursae lie posteriorly in L3-L5 interspinous spaces (arrows).

T2-weighted sagittal fast spin echo (repetition time ms/echo time ms, 3000/100) and T1-weighted sagittal and axial fast spin echo (500/20) with fat saturation before and after contrast medium scans. Section thickness was $3 \mathrm{~mm}$ with an intersection gap of $0.3 \mathrm{~mm}$. The field of view was $24 \mathrm{~cm}$ and $32 \mathrm{~cm}$ and the matrix size was $512 \times 512$ and $384 \times 224$ at the cervical and lumbar level, respectively. A bolus of $0.2 \mathrm{ml}$ of gadoterate meglumine (Dotarem; Laboratoire Guerbet, Aulnay-sous-Bois, France) per kilogram of body weight was injected manually through a catheter inserted into an antecubital vein and followed by a $20 \mathrm{ml}$ saline solution.

MRI images were examined by a radiologist (LB) who was blinded to the clinical findings and the diagnosis.

Cervical and lumbar bursae were evaluated for fluid collection. As shown in figs 2 and 3, measurement of fluid accumulation was graded using a semiquantitative scale:
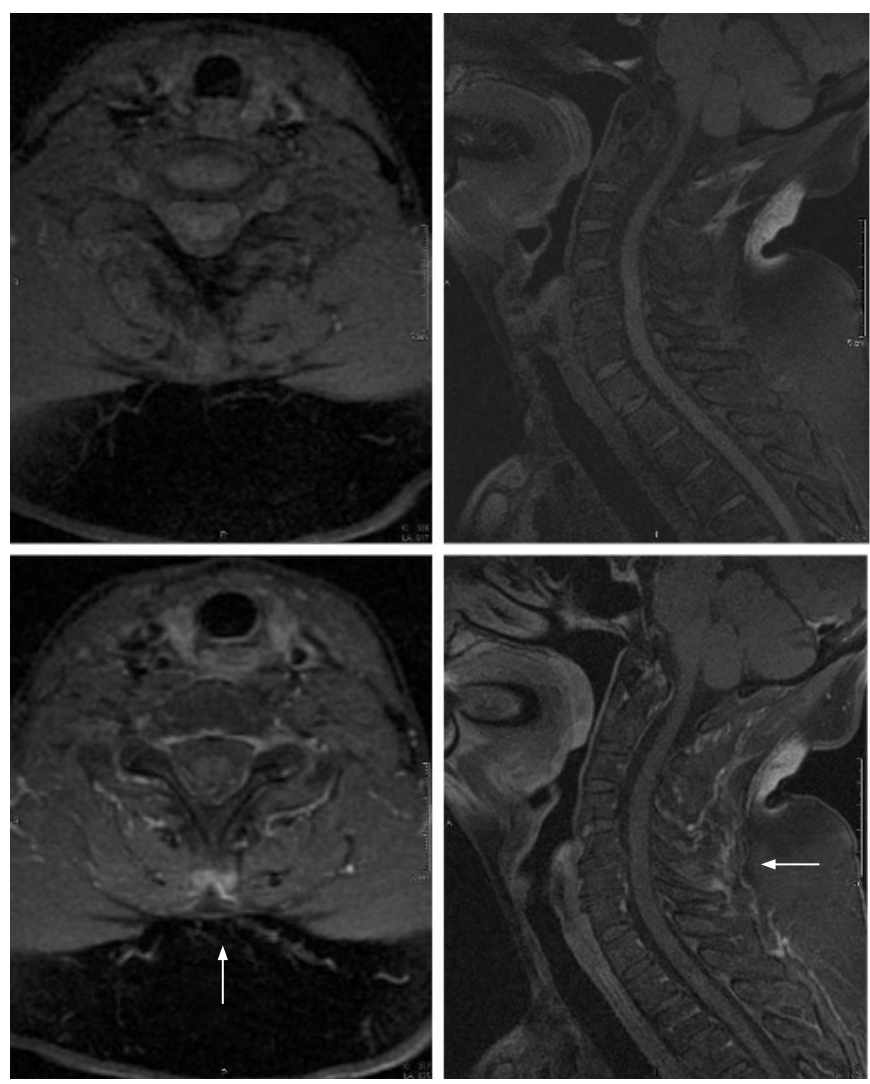

Figure 2 Mild cervical interspinous bursitis. T1-weighted axial and sagittal fast spin echo with fat saturation before and after contrast medium scans. Contrast enhancement at level of bursae (arrows).

$0=$ no accumulation; $1=$ sufficient accumulation to allow visualisation of the bursae (mild bursitis), $2=$ moderate accumulation (moderate bursitis) and $3=$ sufficient quantity to stretch the walls of structures (marked bursitis).

Statistical analysis was performed using the SPSS V.13 program (SPSS Inc., Chicago, Illinois, USA). The Fisher exact test was used to compare the frequencies.

\section{RESULTS}

In all 12 patients with PMR, MRI showed the presence of fluid in the cervical interspinous bursae at the C5-C7 level suggesting bursitis (figs 2 and 3 , table 1 ).

Fluid accumulation in the cervical interspinous bursae at the same level was also observed in 6 of the 13 control patients (3 patients with fibromyalgia, 2 with psoriatic spondylitis and 1 with cervical osteoarthritis). Of the four patients with primary AS, none showed signs of cervical bursitis.

Moderate to marked (grade $\geqslant 2$ ) cervical bursitis occurred significantly more frequently in case patients than in control patients (83.3\% compared with $30.7 \%, p=0.015)$. Cervical bursitis was found in all case and control patients at the C5-C7 cervical interspaces. No erosions of spinous processes on MRI were observed.

Moderate (grade 2) and marked (grade 3) lumbar bursitis at the L3-L5 lumbar interspaces were respectively observed in the two patients with PMR and pelvic girdle pain who underwent MRI of the lumbar spine. Throughout the follow-up period (median: 14 months, range: 10-16 months), no patient with PMR fulfilled American College of Rheumatology (ACR) 1987 criteria for rheumatoid arthritis $(\mathrm{RA})^{13}$ or developed other conditions. 
Table 1 Demographic and clinical findings and results of magnetic resonance imaging of 13 patients with polymyalgia rheumatica

\begin{tabular}{|c|c|c|c|c|c|c|c|c|c|c|}
\hline \multirow[b]{2}{*}{ Sex } & \multirow[b]{2}{*}{ Age (years) } & \multirow{2}{*}{$\begin{array}{l}\text { Disease duration } \\
\text { at diagnosis } \\
\text { (months) }\end{array}$} & \multicolumn{3}{|c|}{ Aching and stiffness } & \multirow{2}{*}{$\begin{array}{l}\text { Systemic } \\
\text { symptoms and } \\
\text { signs* }\end{array}$} & \multirow[b]{2}{*}{$\operatorname{ESR}(\mathrm{mm} / \mathrm{h})$} & \multirow[b]{2}{*}{$\begin{array}{l}\text { Cervical bursitis } \\
\text { at MRI } \dagger\end{array}$} & \multirow{2}{*}{$\begin{array}{l}\text { Cervical interspaces } \\
\text { where bursae were } \\
\text { found }\end{array}$} & \multirow{2}{*}{$\begin{array}{l}\text { Follow-up period } \\
\text { after diagnosis } \\
\text { (months) }\end{array}$} \\
\hline & & & $\begin{array}{l}\text { Shoulder } \\
\text { girdle }\end{array}$ & Neck & $\begin{array}{l}\text { Pelvic } \\
\text { girdle }\end{array}$ & & & & & \\
\hline $\mathrm{F}$ & 69 & 3 & Yes & Yes & Yes & Yes & 75 & 2 & C5-C7 & 10 \\
\hline $\mathrm{F}$ & 71 & 3 & Yes & Yes & No & No & 78 & 2 & $\mathrm{C} 5-\mathrm{C} 7$ & 12 \\
\hline $\mathrm{F}$ & 74 & 3 & Yes & Yes & No & No & 62 & 3 & $\mathrm{C} 5-\mathrm{C7}$ & 16 \\
\hline $\mathrm{F}$ & 69 & 4 & Yes & Yes & No & No & 52 & 3 & $\mathrm{C} 5-\mathrm{C} 7$ & 14 \\
\hline $\mathrm{F}$ & 72 & 3 & Yes & Yes & Yes & No & 64 & 2 & $\mathrm{C} 5-\mathrm{C} 7$ & 16 \\
\hline $\mathrm{F}$ & 80 & 4 & Yes & Yes & No & No & 48 & 2 & C5-C7 & 12 \\
\hline M & 67 & 3 & Yes & Yes & No & Yes & 51 & 2 & $\mathrm{C} 5-\mathrm{C} 7$ & 14 \\
\hline $\mathrm{F}$ & 64 & 2 & Yes & Yes & No & Yes & 68 & 3 & $\mathrm{C} 5-\mathrm{C} 7$ & 13 \\
\hline M & 74 & 3 & Yes & Yes & Yes & No & 74 & 1 & $\mathrm{C} 5-\mathrm{C} 7$ & 14 \\
\hline
\end{tabular}

${ }^{*}$ Systemic symptoms and signs are defined by the presence of at least one of the following: fever, anorexia or weight loss.

$\uparrow$ The entity of fluid collection was graded with a semiquantitative scale: $0=$ no fluid collection; $1=$ sufficient fluid collection to visualise bursae (mild bursitis); $2=$ moderate fluid collection (moderate bursitis); 3 = fluid sufficient to stretch the walls of structures (marked bursitis).

ESR, erythrocyte sedimentation rate.

\section{DISCUSSION}

The prevalence, distribution and pathology of cervical interspinous bursitis in a series of random necropsies from "normal" adult necks and in the spines of patients with inflammatory arthropathies were described by Bywaters in 1982.' Bursal spaces were found between the cervical spinous processes at necroscopy in 14 of 27 "normal" necks. Their presence in
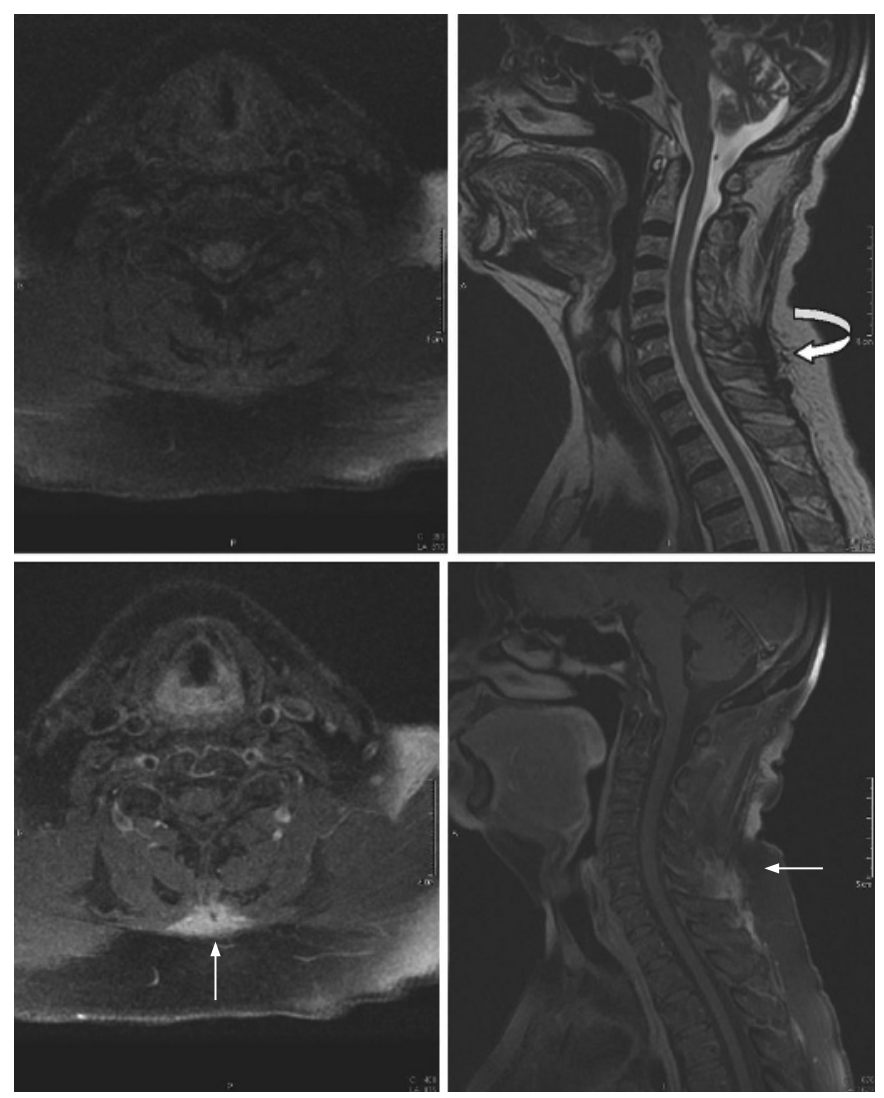

Figure 3 Marked cervical interspinous bursitis. T1-weighted sagittal fast spin scan before contrast medium. Thickness of bursae (curved arrow). T1-weighted fast spin echo with fat saturation before (axial) and after contrast medium (axial and sagittal) scans. High contrast enhancement at level of bursae (arrows). "normal" necks was linked to the proximity of the spinous processes to each other, likely to lead to ligamentous alterations and laxity. The posterior instability and the consequent excessive motion between adjacent, closely apposed, spinous processes may stimulate the formation of interspinous bursae. ${ }^{14}$

These bursae consist of narrow slits generally located near the undersurface of the upper spinous process, extending at variable distances dorsally from the ligamentum flavum (fig 1). They were found most frequently at the C6-C7 level but also at all other cervical interspaces except C1-C2. The lining consisted microscopically of sparse synovial cells on a bed of fibro-adipose tissue.

The presence of cervical interspinous bursitis in "normal" spine may be mapped to posterior cervical pain. This pain was episodic in nature, exacerbated by neck extension and responsive to local injection of anaesthetic. ${ }^{915}$

In the same necroscopic study Bywaters also evaluated the presence of cervical bursitis in five patients with juvenile chronic arthritis and in nine patients with adult-onset RA. ${ }^{9}$ Cervical bursitis characterised by synovial lining hyperplasia and erosions of the spinous processes was demonstrated in two patients with the juvenile and in two with the adult form of RA. Finally, calcium pyrophosphate dihydrate (CPPD) and hydroxyapatite crystal deposition have both been identified in the interspinous bursae and may be associated with radiographic evidence of chondrocalcinosis at other sites. ${ }^{9}{ }^{12}$ In this regard, CPPD has been reported to mimic isolated PMR and thus CPPD must be excluded in patients presenting with PMR symptoms. ${ }^{16}$

Our study provides for the first time evidence that moderate to marked bursitis at the C5-C7 cervical interspaces on MRI is significantly more frequent in patients with PMR than in controls with various inflammatory and non-inflammatory disorders.

The rationale behind this study is based on the one hand on the clinical observation that patients with PMR typically complain of neck and girdle pain, suggesting an inflammatory process at these sites, and on the other hand on the results of previous imaging studies, which suggest involvement of articular and of extra-articular structures (particularly bursae) in PMR. ${ }^{3-611}$ Blockmans et al demonstrated that the vast majority of patients with PMR have increased FDG uptake in the shoulders and in the hips, in agreement with the concept 
that PMR is characterised by an underlying synovitis of these joints. ${ }^{11}$ However, half of the patients investigated by Blockmans also showed abnormal FDG uptake in the region of vertebral spinous processes, although FDG-PET due to its low resolution was not able to identify the specific anatomical structures involved. In previous imaging studies, we found that bilateral subacromial and subdeltoid bursitis was the most frequent lesion present in almost all patients with PMR with shoulder pain, while bilateral trochanteric bursitis represented the most frequent hip lesion in those with hip symptoms. ${ }^{3-6}$ These studies confirmed the involvement of extra-articular synovial structures, in particular bursae, in PMR. ${ }^{78}$ On the basis of these and of Bywater's study findings, we decided to investigate whether PMR might also be characterised by interspinous bursitis using contrast-enhanced MRI.

The results of this study support the hypothesis that inflammation of the cervical interspinous bursae may contribute to the pain in the neck reported by patients with PMR. This notion is further strengthened by the observation that the pain is prevalently felt at the level of the C6-C7 spinous processes and likely radiates laterally to the broader cervical area. $^{17}$

With regard to the lumbar bursae, Bywaters and Evans in a pathology study in 1982 investigated the topography and the involvement of lumbar interspinous bursae in various rheumatic disorders. ${ }^{10}$ However, even in 1933 Baastrup had already recognised that inflammation of lumbar bursae might cause localised midline lumbar tenderness and pain on backward extension relieved by flexion and local anaesthetics. ${ }^{18}$ The bursae most frequently involved were those at the L4-L5 level, however if more than one space was involved they were usually adjacent, mostly at the L4-L5 and the L3-L4 level. In the lumbar area the bursae lie posteriorly (fig 1), which is different from the cervical spine where the bursae lie anteriorly in the intraspinous space. ${ }^{19}$ The frequency of the presence of these bursae increases with the age. They are not present under 10 years of age, while at the ages of $61-70$ years, $85 \%$ of the patients showed L4-L5 bursae.

In our study, inflammatory involvement of the bursae at the L3-L4 lumbar interspaces was observed in the two patients with pelvic girdle pain who were investigated by MRI. The inflammation of these bursae may contribute to the low back pain that occurs together with the hip girdle pain in patients with PMR. However, the association between lumbar bursitis and PMR remains to be demonstrated in an imaging casecontrol study.

Possible limitations of our study are the small number of patients enrolled, lack of repeat examinations after therapy, and absence of comparison patients with a systemic inflammatory arthritis such as RA. However our results are strengthened by the inclusion of two control groups, including patients with non-inflammatory and inflammatory conditions.
In conclusion, cervical bursitis is likely to contribute to the discomfort in the neck of patients with PMR. Inflammation of lumbar bursae may also be responsible for the low back pain reported by a patient with PMR with hip girdle involvement. The prominent inflammatory involvement of cervical and lumbar bursae supports the hypothesis that PMR may be a disorder affecting predominantly extra-articular synovial structures, in particular of bursae..$^{8}$

Acknowledgements: We would like to thank Giliola Gamberini from "Scuola di Disegno Anatomico", Istituto Ortopedico Rizzoli, Bologna, Italy, for providing the anatomic figures showing the location of interspinous bursae.

Competing interests: None declared.

\section{REFERENCES}

1. Salvarani C, Cantini F, Boiardi L, Hunder GG. Polymyalgia rheumatica and giant-cell arteritis. N Engl J Med 2002;347:261-71.

2. Meliconi R, Pulsatelli L, Uguccioni M, Salvarani C, Macchioni P, Melchiorri C, et al. Leukocyte infiltration in synovial tissue from the shoulder of patients with polymyalgia rheumatica. Quantitative analysis and influence of corticosteroid treatment. Arthritis Rheum 1996;39:1199-207.

3. O'Duffy JD, Wahner HW, Hunder GG. Joint imaging in polymyalgia rheumatica. Mayo Clin Proc 1976;51:519-24.

4. Salvarani C, Cantini F, Olivieri I, Barozzi L, Macchioni PL, Piccoli L, et al. Proximal bursitis in active polymyalgia rheumatica. Ann Intern Med 1997;27:27-31.

5. Cantini F, Salvarani C, Olivieri I, Niccoli L, Padula A, Macchioni PL, et al. Shoulder ultrasonography in the diagnosis of polymyalgia rheumatica: a case-control study. J Rheumatol 2001;28:1049-55

6. Cantini F, Niccoli L, Nannini C, Padula A, Olivieri I, Boiardi L, et al. Inflammatory changes of hip ynovial structures in polymyalgia reumatica. Clin Exp Rheumatol 2005;23:462-8

7. Salvarani C, Cantini F, Olivieri I, Hunder GG. Polymyalgia rheumatica: a disorder of extraarticular synovial structures? J Rheumatol 1999;26:517-21.

8. Salvarani C, Olivieri I, Cantini F, Hunder GG. Classification of inflammatory arthritis: the place of polymyalgia rheumatica. Lancet 1998;352:1938.

9. Bywaters EG. Rheumatoid and other diseases of the cervical interspinous bursae and changes in the spinous process. Ann Rheum Dis 1982;41:360-70.

10. Bywaters EGL, Evans S. The lumbar interspinous bursae and Baastrup's syndrome An autopsy study. Rheumatol Int 1982;2:87-96.

11. Blockmans D, De Ceuninck L, Vanderschueren S, Knockaert D, Mortelmans L, Bobbaers H. Repetitive 18-fluorodeoxyglucose positron emission tomography in isolated polymyalgia rheumatica: a prospective study in 35 patients. Rheumatology (Oxford) 2007:46:672-7.

12. Van der Linden S, Valkenburg HA, Cats A. Evaluation of diagnostic criteria for ankylosing spondylitis: a proposal for modification of the New York criteria. Arthritis Rheum 1984:27:361-8.

13. Arnett FC, Edworthy SM, Bloch DA, McShane DJ, Fries JF, Cooper NS, et al. The American Rheumatism Association 1987 revised criteria for the classification of rheumatoid arthritis. Arthritis Rheum 1988;31:315-24.

14. Sartoris DJ, Resnick D, Tyson R, Haghighi P. Age-related alterations in the vertebral spinous processes and intervening soft tissues: radiologic-pathologic correlation. Am J Roentgenol 1985;145:1025-30.

15. Jung A, Vierling JP. Role of the kissing spine syndrome in cervical algias. Ann Chir 1964:18:1280-6.

16. Pego-Reigosa JM, Rodriguez-Rodriguez M, Hurtado-Hernandez Z, Gromaz-Martin J, Taboas-Rodriguez D, Millan-Cachinero C, et al. Calcium pyrophosphate deposition disease mimicking polymyalgia rheumatica: a prospective followup study of predictive factors for this condition in patients presenting with polymyalgia symptoms. Arthritis Rheum 2005;53:931-8.

17. Coomes EN, Sharp J. Polymyalgia rheumatica. A misnomer? Lancet 1961;2:1328-31.

18. Baastrupt Cl. Proc. spin. vert. lumb. Und einige zwischen diesen liegende Gelenkbildungen mit Pathologischen-Prozessen in dieser Region. ROFO 1933;48:430-5.

19. François RJ, Bywaters EGL, Aufdermaur M. Illustrated glossary for spinal anatomy. Rheumatol Int 1985;5:241-5. 